\title{
Renal Clinical - Pathological Manifestations in Bullous Pemphigoid
}

\author{
Ke-Zhong Zhao", Zhang Lian, Jian-Feng Liu, Yong-Hong Cai, Rui-Hong Han, Zhang Yan, \\ Jin-Lei Wang, Yin-Lin Wang and Zhao Jin
}

Jinghai Clinical College, Tianjin Medical University, Tianjin, P.R. China

\begin{abstract}
A 61-year old man was admitted with a 2-month history of skin rash, and proteinuria and intermittent hemoptysis for 2 weeks. The patient had developed circular erythema and blisters all over the body with scab formation. Edema of the legs and eyelids appeared 2 weeks prior to admission. Kidney biopsy showed membranous nephropathy (phase II) with focal segmental mesangial proliferation and deposits of IgG along the GBM. Skin biopsy demonstrated IgG deposits in the epidermal basement membrane zone. The simultaneous development of a rare renal and skin autoimmune disorder, resulting from non-cross-reactive autoantibodies, suggests that a common triggering event could be responsible for the autoimmune injury. This patient with bullous pemphigoid was treated with corticosteroids, which were tapered to an acceptable and effective maintenance dose following treatment with intravenous cyclophosphamide.
\end{abstract}

Keywords: Bullous pemphigoid, immunosupressant treatment, renal injury.

\section{INTRODUCTION}

Bullous pemphigoid (BP) is a skin disease that causes blisters. It affects mainly people over 60 years of age. We report a patient with bullous pemphigoid who presented with cutaneous lesions and nephrotic syndrome. Renal pathological diagnosis was membranous nephropathy (phase II) with focal segmental mesangial proliferation. Treatment with corticosteroids and other immunossupressives effectively controlled symptoms.

\section{CASE REPORT}

A 61-year old man was admitted with a 2-month history of skin rash and proteinuria and intermittent hemoptysis for 2 weeks. The patient had developed circular erythema and blisters all over the body with scab formation. Edema of the legs and eyelids appeared 2 weeks prior to admission. The patient was previously well, was not on medication before the skin eruption, had no systemic signs, was afebrile and normotensive. There was generalised circular erythema and blisters with scabs throughout the body. The blisters were firm and dome-shaped, and ranged from $10 \mathrm{~mm}$ to $20 \mathrm{~mm}$ (Fig. 1). Palpebral and pedal edema and congested throat were present. The white blood cell count was $6.2 \times 10^{9} / \mathrm{L}$, with a differential of $78 \% \mathrm{~N}, 17 \% \mathrm{~L}$ and $5 \% \mathrm{M}$ and a platelet count of $2.06 \times 10^{11} / \mathrm{L}$. Urinary RBC of $0-2 / \mathrm{HP}$ and $24 \mathrm{~h}$ urinary protein of $7.7 \mathrm{~g}$ was present. Serum $\mathrm{IgG}, \mathrm{IgA}$ and $\operatorname{IgM}$ were $7.98 \mathrm{~g} / \mathrm{L}, 1.37 \mathrm{~g} / \mathrm{L}$, and $1.63 \mathrm{~g} / \mathrm{L}$ respectively. $\mathrm{C} 3$, C4, ALT and AST were normal. The ESR was $60 \mathrm{~mm} / \mathrm{h}$. Serum Albumin/Globulin 18.9/27.4 g/L, total cholesterol CHO $11.23 \mathrm{mmol} / \mathrm{L}$, TG $2.55 \mathrm{mmol} / \mathrm{L}$ and LDL-C $8.94 \mathrm{mmol} / \mathrm{L}$.

*Address correspondence to this author at the Department of Nephrology, Jinghai Clinical College, Tianjin Medical University, Tianjin, P.R. China; Tel: +86-22-68924230; Fax: +86-22-28942928; E-mail: Kzz2568@126.com

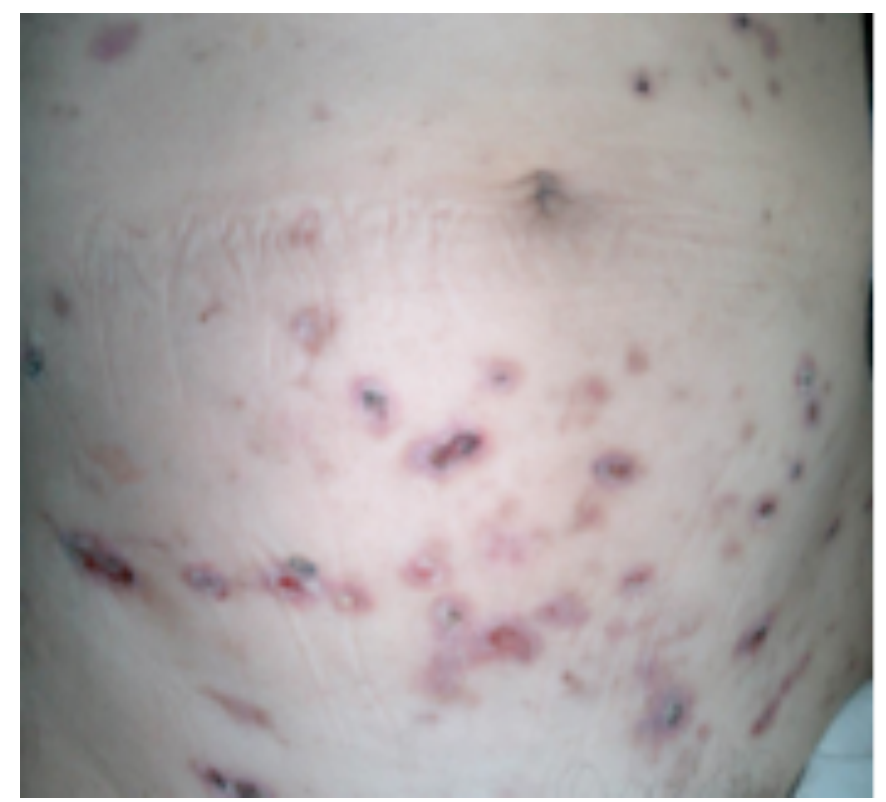

Fig. (1). Bullous pemphigoid; cutaneous biopsy $H E$ stain (10X).

RF, ASO, ANA, HbsAg, c-ANCA, p-ANCA, anti-MPO and anti-PR3 were negative. The titers of nucleolar pattern ANA were $1: 3200$. TSH, $\mathrm{T}_{3} \mathrm{~F}$ and $\mathrm{T}_{4} \mathrm{~F}$ were normal. Renal ultrasound demonstrated bilateral normal sized kidneys. Light microscopy of the skin biopsy showed blisters under the cutis, with dilatation and congestion of the capillaries of the upper dermis, and infiltration of eosinophils, lymphocytes and plasma cells (Fig. 2). Renal biopsy showed glomerular mesangial cell proliferation with thickening and stiffness of the glomerular capillary loops (Fig. 3). Renal tubular epithelial cells showed granular denaturation, cystic dilatation and focal atrophy. Proteinaceous casts were present in the tubules. Focal inflammatory cell infiltration and focal fibrosis were present in the renal interstitium. With Masson staining, small red subepithelial deposits could be 
observed (Fig. 4). Granular IgG deposits were present along the glomerular capillary wall. IgA, IgM, C3, C1q and Fib were negative (Fig. 5). Electron microscopy demonstrated mild focal segmental proliferation of glomerular mesangial cells and matrix, a few deposits in the glomerular mesangium and diffuse thickening of the basement membrane. Scattered electron dense subepithelial immune deposits and spikes could be found. The foot processes of podocytes were effaced and fused. Tubular atrophy was not obvious. Denatured fat and protein were present in the epithelial cells (Fig. 6). The renal pathological diagnosis was membranous nephropathy (phase II) with focal segmental mesangial proliferation.

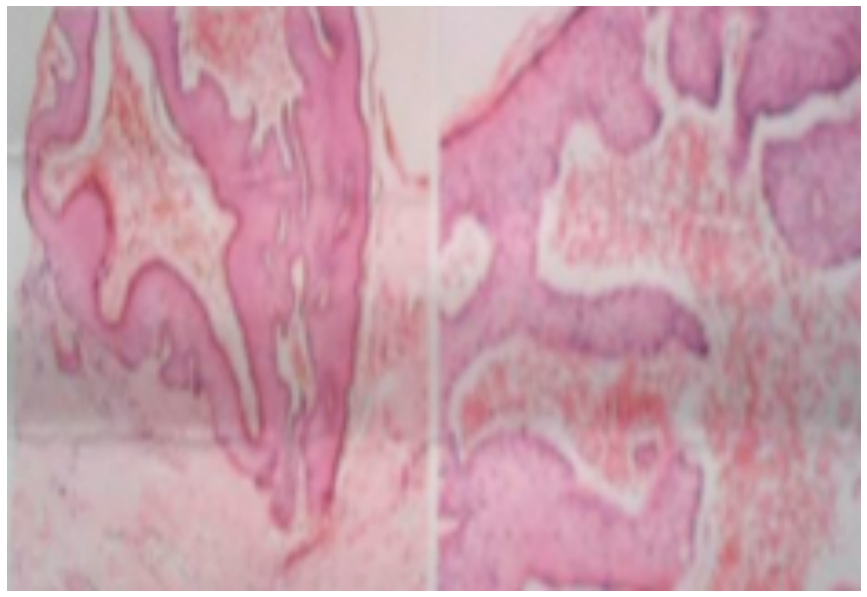

Fig. (2). Blisters were seen under the cutis. The capillaries of the upper dermis were dilated and congested, and infiltrated by eosinophils, lymphocytes and plasma cells.

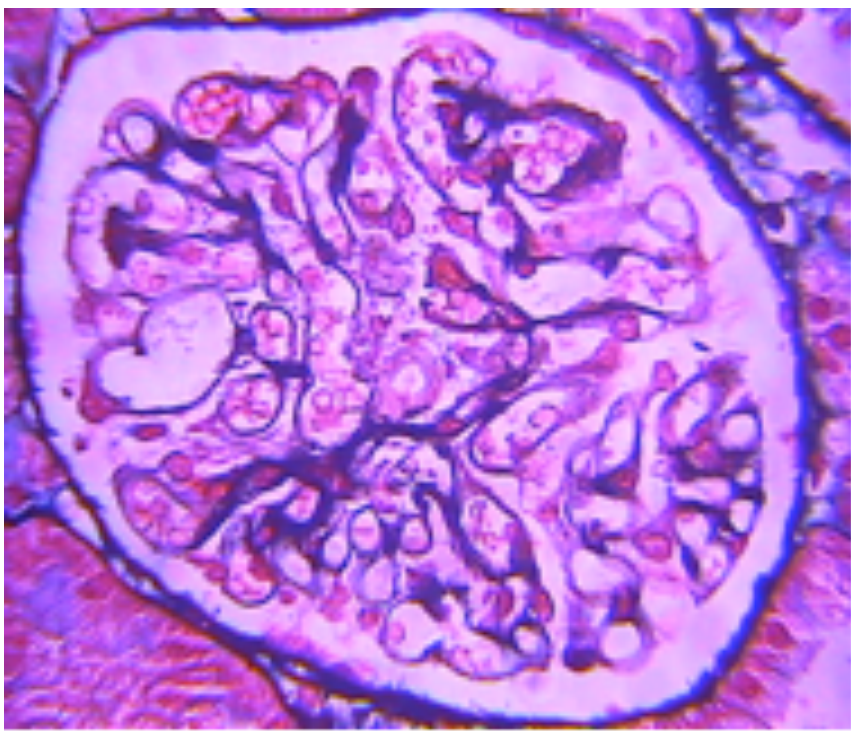

Fig. (3). Glomerular mesangial cells proliferation, Dilated and stiff glomerular capillary loops were present were dilated and stiff.

He was treated with prednisone acetate $60 \mathrm{mg}$ poqd for 8 -weeks, before being tapered off, and dipyridamole, benazepril hydrochloride and alprostadil. Plasma albumin increased to $22.7 \mathrm{~g} / \mathrm{L}$ and the 24 h-urinary protein decreased to $5.28 \mathrm{~g}$ after treatment. Intravenous cyclophosphamide $1.0 \mathrm{~g} / \mathrm{month}$ was given at this time and after two months,

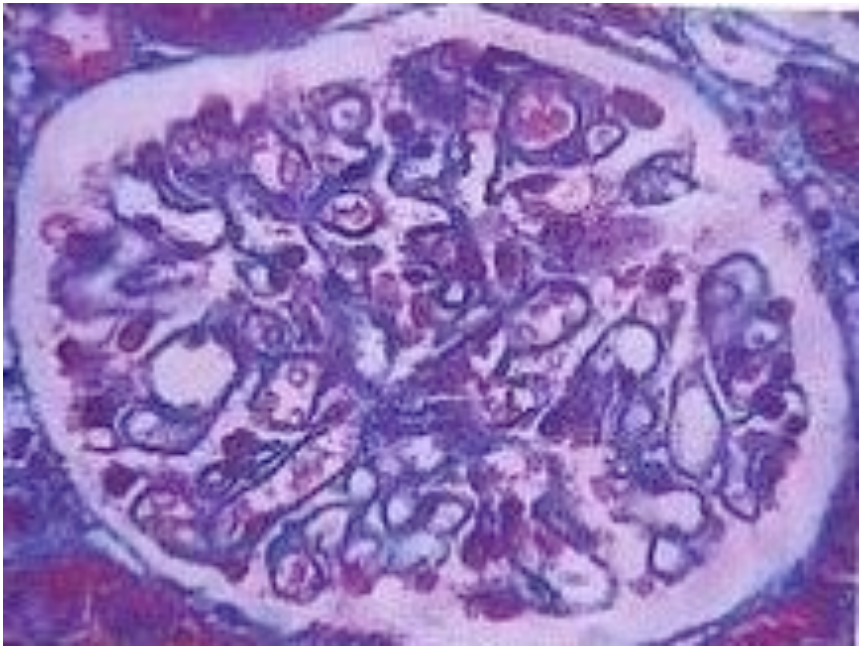

Fig. (4). With Masson staining: small red subepithelial deposits could be observed.

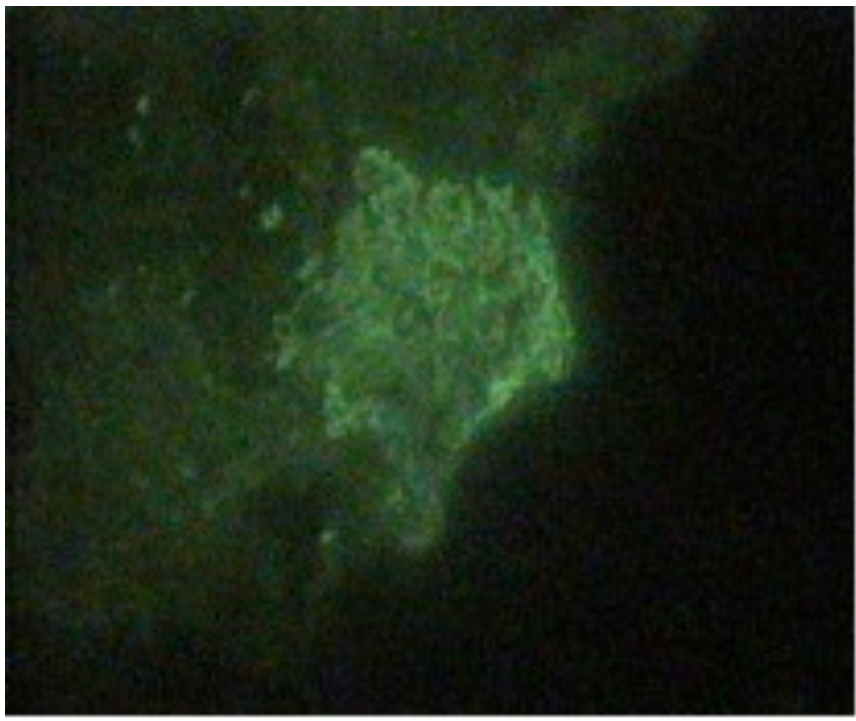

Fig. (5). Granular IgG deposits were present along the glomerular capillary wall.

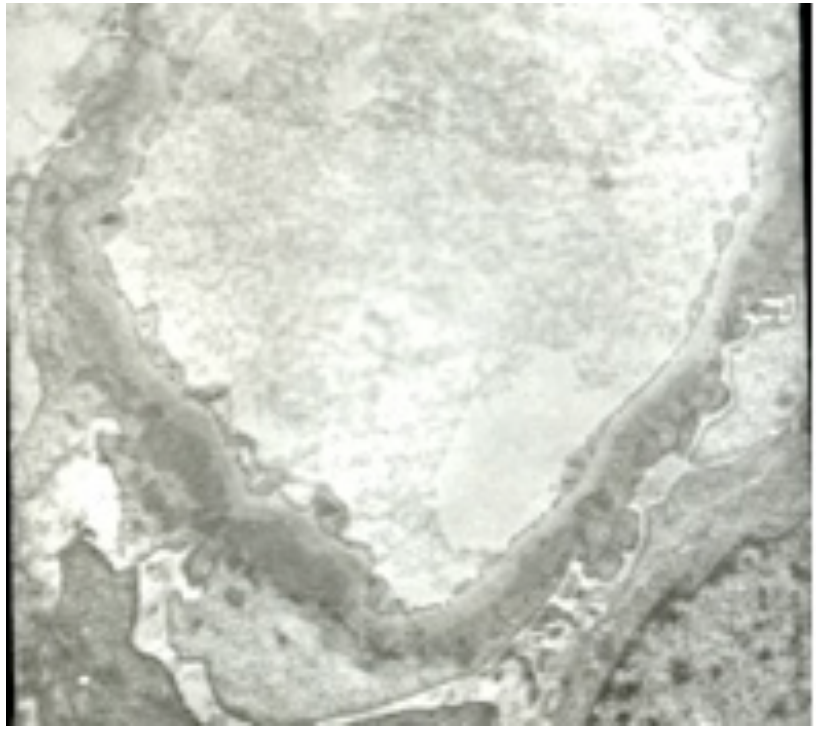

Fig. (6). Electron microscopy DDD (5000X). 
Table 1. Response to treatment of bullous pemphigoid.

\begin{tabular}{|c|c|c|c|c|c|c|c|c|}
\hline \multirow[t]{2}{*}{ Date } & \multirow{2}{*}{$\begin{array}{l}\text { Alb } \\
\text { g/L }\end{array}$} & \multirow{2}{*}{$\begin{array}{l}\text { Glo } \\
\text { g/L }\end{array}$} & CHO & TG & \multirow{2}{*}{$\begin{array}{c}\text { ESR } \\
\mathrm{mm} / \mathrm{h}\end{array}$} & \multirow{2}{*}{$\begin{array}{c}\text { Urinary Protein } / 24 h \\
g / 24 h\end{array}$} & \multirow{2}{*}{$\begin{array}{l}\text { Pred } \\
\mathrm{mg} / \mathrm{d}\end{array}$} & \multirow{2}{*}{$\begin{array}{c}\text { Cyclophosphamide } \\
\text { G }\end{array}$} \\
\hline & & & \multicolumn{2}{|c|}{$\mathrm{mmol} / \mathrm{L}$} & & & & \\
\hline 2006.11 .15 & 18.9 & 27.4 & 11.23 & 2.55 & 60 & 7.706 & 60 & Renal biopsy \\
\hline 2007.1 .15 & 22.7 & 26.5 & & & & 5.28 & 55 & 1.0 \\
\hline 2007.2 .16 & 33.2 & 25.3 & 7.36 & 2.6 & 21 & 4.61 & 50 & 1.0 \\
\hline 2007.3 .13 & 35.9 & 22.3 & 7.42 & 1.75 & 15 & 2.13 & 45 & 1.0 \\
\hline 2007.4 .15 & 33.3 & 17.5 & 6.04 & 2.0 & & 1.48 & 35 & 1.0 \\
\hline 2077.5 .16 & 34.5 & 15.6 & 6.77 & 1.72 & & 0.79 & 25 & 1.0 \\
\hline 2007.8 .8 & 37.0 & 15.7 & 5.49 & & & 0.248 & 20 & 1.0 \\
\hline 2007.11 .8 & 42.9 & 21.1 & 6.06 & 1.18 & & 0.186 & $10-7.5$ & 0.8 \\
\hline 2008.2 .26 & 42.6 & 22.2 & 4.93 & 1.19 & & 0.037 & - & - \\
\hline 2012.5 .28 & 43.6 & 26.1 & 4.82 & 1.26 & & 0.058 & - & - \\
\hline
\end{tabular}

bullous pemphigoid lesions disappeared. Levels of plasma albumin were $35.9 \mathrm{~g} / \mathrm{L}$ and the $24 \mathrm{~h}$-urinary protein $2.13 \mathrm{~g}$. The titers of nucleolar pattern ANA was reduced to 1:320 and lipid levels and ESR normalised. After 7 doses of intravenous cyclophosphamide over 11 months, plasma albumin increased to $42.6 \mathrm{~g} / \mathrm{L}$ and $24 \mathrm{~h}$-urinary-protein was normal $(33.8 \mathrm{mg} / \mathrm{d})$. The patient was cured after 51 months (Fig. 1).

\section{DISCUSSION}

Bullous pemphigoid (BP) is a subepidermal autoimmune bullous skin disease. It is associated with autoantibodies directed against the BP antigens 180 (BPAG2) and BP230 (BPAG1). The pathogenicity of anti-BP180 antibodies has been convincingly demonstrated in animal models. The clinical features of BP are extremely pleomorphic. The diagnosis of BP critically relies on immunopathologic findings. The recent development of novel enzyme-linked immunosorbent assays has allowed the detection of circulating autoantibodies with relatively high sensitivity and specificity [1].

It is mediated by circulating antibodies directed against two hemidesmosomal proteins of the dermal epidermal junction: BPAG1 and BPAG2. Clinical features consist of pruritus and tense blisters usually surrounded by erythema. Blisters sometimes evolve to erosions, become haemorrhagic and can progress to large erosive areas. Lesions heal without scarring. Lesions are symmetrically located on the thighs, legs, trunk and arms. Mucous membranes are usually uninvolved. Histological examination of a skin biopsy specimen shows a subepidermal blister with eosinophils within the blister and the superficial dermis. Direct immunofluorescence shows linear IgG and/or C3 deposits along the dermal epidermal junction [2].

Proinflammatory cytokines such as TNF- $\alpha$, IL-6 and Th1-like cytokines (IL-2 and INF- $\gamma$ ) are not detected, neither as proteins nor as mRNA. Since IL-4 and IL-5 are important in eosinophil chemoattraction, maturation and functional activity, the presence of IL-4 and IL-5 in BP suggest that these cytokines could be important in the pathogenesis of the disease [3].

The patient had deposits of $\mathrm{IgG}$ in the kidney and the skin, along the GBM and the epidermal basement membrane zone respectively. The patient's autoantibodies immunoblotted the intracellular domain but not the extracellular domain of BP180. Reactivity of the patient's IgG with BP180 was found only in the unbound fraction of the serum. The simultaneous development of a rare renal and skin autoimmune disorder, resulting from non-cross-reactive autoantibodies, suggests that a common triggering event could be responsible for the autoimmune injury [4].

In bullous pemphigoid, azathioprine and mycophenolate mofetil seem to be equally effective when used in combination with oral corticosteroids, but mycophenolate mofetil is less myelosuppressive and hepatotoxic. Cyclophosphamide still has a place in the treatment of severe relapsing autoimmune bullous diseases. Several pulsed cyclophosphamide regimens have, therefore, been developed and are reported to be effective in severe forms of pemphigus. Randomized controlled studies are needed to compare the efficacy and safety of cyclophosphamide with newer treatment options, such as rituximab and immunoapheresis, and to define optimal dose ranges and duration of available immunosuppressive treatments in different stages of autoimmune bullous diseases [5].

\section{CONFLICT OF INTEREST}

The authors confirm that this article content has no conflict of interest.

\section{ACKNOWLEDGEMENTS}

Declared none.

\section{REFERENCES}

[1] Di Zenzo G, Della Torre R, Zambruno G, et al. Bullous pemphigoid: from the clinic to the bench. Clin Dermatol 2012; 30(1): 3-16. 
[2] de Quatrebarbes J, Joly P. Bullous pemphigoid. Rev Prat 2005; 55(11): 1165-8.

[3] Feliciani C, Toto P, Mohammad Pour S, et al. A Th2-like cytokine response is involved in bullous pemphigoid. The role of IL-4 and IL-5 in the pathogenesis of the disease. Int $\mathrm{J}$ Immunopathol Pharmacol 1999; 12(2): 55-61.
[4] Plaisier E, Borradori L, Hellmark T, et al. Anti-glomerular basement membrane nephritis and bullous pemphigoid caused by distinct anti-alpha 3(IV)NC1 and anti-BP180 antibodies in a patient with Crohn's disease. Am J Kidney Dis 2002; 40(3): 649-54.

[5] Meurer M. Immunosuppressive therapy for autoimmune bullous diseases. Clin Dermatol 2012; 30(1): 78-83.

(C) Zhao et al.; Licensee Bentham Open.

This is an open access article licensed under the terms of the Creative Commons Attribution Non-Commercial License (http://creativecommons.org/licenses/by-nc/3.0/) which permits unrestricted, non-commercial use, distribution and reproduction in any medium, provided the work is properly cited. 